\title{
Experimental Study of Hardness Measurement affected by a Cushion between Probe and PTF Pressure sensor
}

\author{
Hideki Toda ${ }^{1}$, Natsumi Takata ${ }^{2}$, Motoki Okumura ${ }^{3}$
}

Department of Electric and Electronic Engineering, University of Toyama, 3190 Gofuku, Toyama, 930-8555, Japan

\begin{abstract}
In this paper, experimental study of hardness measurement process affected by a cushion between the probe and PTF (polymer thick film) pressure sensor was discussed. Hardness sensing for soft material has been one of the important problems in many fields such as foods industry and material science. One difficulty is how to measure the weak contacting force $(0.1$ to few $N)$ stable with the small target deformation by low-cost force sensor such as PTF, and we found the result of the measurement stability depending on a cushion between the probe and PTF sensor. The result shows that (1) the output force value depends on the kind of cushion material (plastic, urethane, rubber, styrene elastomer, etc.), (2) the force value was affected by the sensor probe angle to the target material. This result would be useful to develop and study the hardness sensing process intending to reduce the target deformation.
\end{abstract}

Keywords_Hardness measurement, soft material, cushion, PTF sensor.

\section{INTRODUCTION}

In this paper, hardness measurement process affected by a cushion between the probe and PTF (polymer thick film) type pressure sensor was discussed. Hardness sensing especially for soft material is one of important problem in many fields such as foods industry and material science, including robotics [1-11].For application, the hardness sensing used many fields such as breast cancer diagnosis [6, 12], tension-type headache from the musculoskeletal complaints [13, 14], trapezius muscle hardness changes from the reason of visual display terminal height [15], muscle hardness measurements using ultrasound $[16,17]$, hardness sensing using optical (IR frequency) techniques [18]. As the force sensor, gauge sensor has been used for the hardness measurement. Since gauge sensor measures a distortion of metal, the accuracy of weak force range $(0.1$ to few $\mathrm{N}$ ) inevitably drops, and it is considered difficult to measure the hardness of soft material [3,19-28]. PTF sensor, on the other hand, is designed for weak force range (about 0.1 to $20 \mathrm{~N}$ ), but the high reliability could not be realized by the instability of the contact area change of the two membranes inside the sensor (Fig. 1a).For example, if the shape of the probe contact terminal to the PTF sensor surface (A) is square, the sensor would be pushed by the linear edge (B) of the probe contact terminal (Fig. 1b), and the probe pushing contact area of the membrane is difficult to change linearly by the pushing force. Since the force is measured proportionally the contact area of the two membranes, the shape and contact area change stability of the probe contact terminal is important factor.

(a)

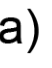

Probe contact terminal

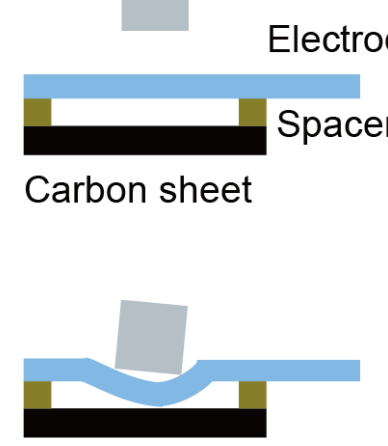

(b)

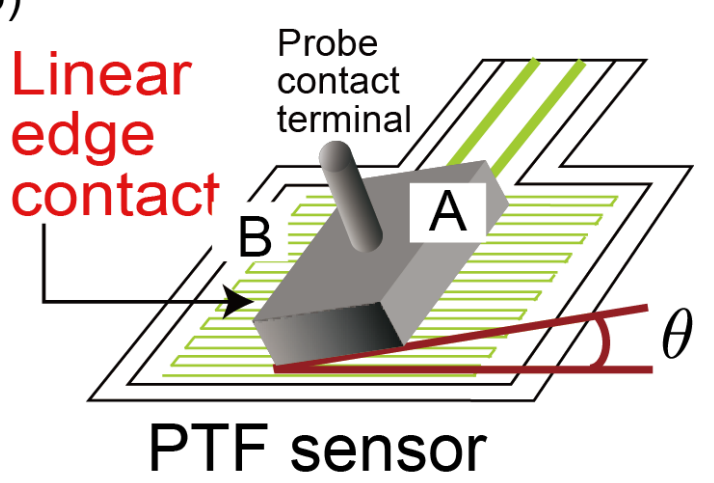

FIgURE 1. EFFECT OF THE SHAPE OF THE PROBE CONTACT TERMINAL CONTACTING WITH PTF SENSOR SURFACE

As shown in Fig.2a, hardness meter is developed by frame, actuator, pushing base, pressure sensor, and "probe body." The probe body contact to the pressure sensor surface and target via the probe part simultaneously. To measure the target object hardness, the actuator force is conveyed to the target via the probe body, and contact situations of the probe body (angle, position, contact place of the target and sensor surface etc.) affect the accuracy and stability of the hardness measurement (Fig.2b). Also, the contact situations cannot control. 
(a)

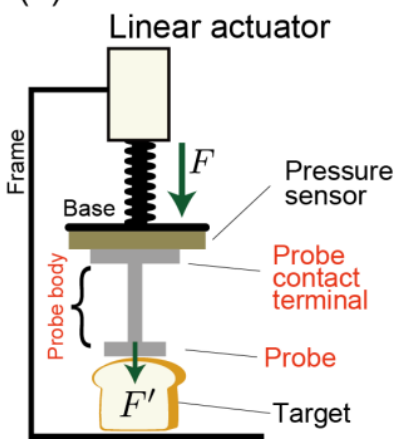

(b)

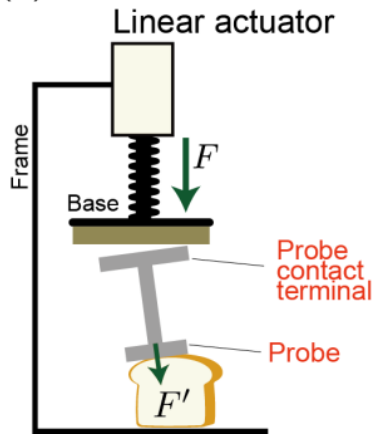

FIGURE 2. EFFECT OF SHAPE OF THE PROBE CONTACT TERMINAL OF THE PROBE.

(a)

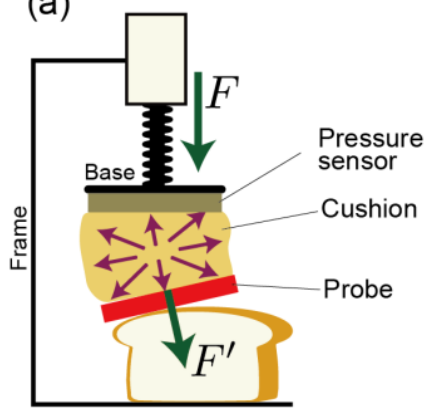

(b)

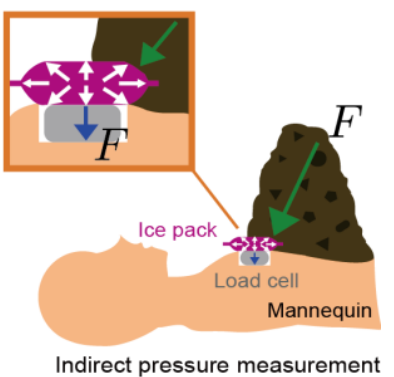

FIGURE 3. (a) ROLE OF THE CUSHION BETWEEN PTF PRESSURE SENSOR AND TARGET MATERIAL. (b) INDIRECT PRESSURE MEASUREMENT OF HUMAN BODY (MANNEQUIN) WHEN SEDIMENT DISASTER BY USING AN ICE PACKS

By adopting a rubber type cushion as the probe body (Fig.3a), it is realized to absorb unevenness of the contact situation, and the target pushing force is correctly transferred to the PTF sensor surface at least. In this paper, the effect of the existence of the cushion as the probe body is examined whiles the hardness measurement.

\subsection{Probe body of cushion}

As shown in Fig.2a, hardness measurement is realized by a hard material's probe body such as metal, and it is important to control and measure the displacement (indent) of the probe by the pushing force [29-31]. It can be realized by the material hardness of the probe body. On the contrary, by using the cushion as the probe body, the accuracy of the control and measurement of the displacement would be reduced. In our approach, by using a cushion that softer than a metal and harder than the target object, it is designed to perform the deformation (indent) of the target by the force while the probe body is deformed to transmit the force to the sensor surface correctly at the same time $[32,33]$. This approach is based on the study of indirect pressure measurement of a human body (mannequin) when sediment disaster (Fig.3b) [34].To measure a pressured force applied to the human body by the sediment, they used a load cell buried in the mannequin. But the measurement force of the load cell is unstable, and it is impossible to measure the correct pressured force with most measurement since the applied force by the sediment is not correctly gained to the load cell's sensor part. Their solution is to use an ice pack as the probe body, and the mechanism is that the force applied to one side appears as a reaction force on each side of the ice pack.

The characteristics of the ice pack required here were as follows: (1) be able to deform but return the shape (not broken), (2) spring constant $k$ ( $\Delta f=k \Delta x, \Delta f$ is force change, $\Delta x$ is displacement change) is larger than the target and lower than the metal type probe body. Necessary other characteristics as material were discussed in the result section.

\section{METHOD}

Fig.4 shows the developed measurement system. It constructed from a linear actuator (RB-Fir-14, DC $12 \mathrm{~V}, 100 \mathrm{~mm}$ stroke, $12.0 \mathrm{~mm} / \mathrm{sec}$, Actuonix Corp.), polymer thick film type pressure sensor (FSR402, 0.2 to $100 \mathrm{~N}$, Interlink Electronics Inc.) and small size rubber cushion ( $2 \mathrm{~mm}$ diameter, thickness $2.5 \mathrm{~mm}$ ), and $10 \mathrm{k} \Omega$ slider potentiometer, $2 \mathrm{~mm}$ thickness acrylic plate $(3 \times 3 \mathrm{~cm})$. The cushion was positioned on the PTF sensor (Fig.4), and the kind of the cushion (plastic, rubber, gel, sponge, air cushion, ice pack) was changed in the experiment. As mentioned above, the role of the cushion is assumed to convey the correct force between the target material surface and the PTF sensor surface. The displacement of the linear actuator's 
pushing distance was measured by a potentiometer inside the linear actuator $(10 \mathrm{k} \Omega)$. The position accuracy of the potentiometer was about $0.55 \mu \mathrm{m}$.

The controller was designed as a simple potentiometer's proportional feedback system since the linear actuator's ball screw mechanisms does not realize quick responses, and the fastest convergence time or the controllability is not required in this paper. The force sensor output was measured 12 bit AD board (Arduino Duo, Arduino Corp.) inside PC via operational amplifier OP-07. The force and the potentiometer's output sampling rate were $10 \mathrm{msec}$.

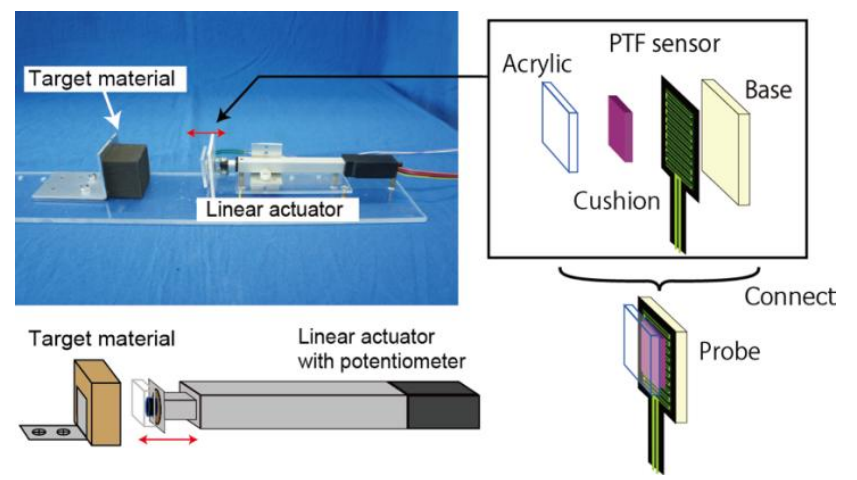

\section{FIGURE 4. EXPERIMENT SETUP OF DEPENDENCIES OF CUSHION MATERIALS.}

\section{EXPERIMENT}

\subsection{Experiment 1: Dependencies of cushion material}

In the experiment 1 , the dependencies of the kind of the cushion material was examined. Table 1 shows tenmaterial's picture and size list used as the cushion, and Table 2 means the material, product name and rough estimate of Young's modulus. As target material, urethane foam sponge $(30 \times 30 \times 50 \mathrm{~mm}$, Young's modulus $\sigma$ about $20 \mathrm{kPa}$, No-\#1, Yahata-neji Corp.) was used, and the key point of the target material was that the $\sigma$ was lower (about one tenth)than the cushion material $\sigma$.

TABLE 1

SPECIFICATION OF CUSHION MATERIALS

\begin{tabular}{|c|c|c|c|c|c|c|c|c|c|c|}
\hline Name & Beads1 & Beads2 & Rubber1 & Rubber2 & Sponge & Air Cushion & IcePack & $\begin{array}{l}\text { Plastic } \\
\text { plate }\end{array}$ & Gel1 & Gel2 \\
\hline Picture & & & & & & & 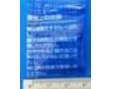 & & & \\
\hline Shape & & & 10 & 0 & $\infty$ & Soft & Soft & & & $\infty$ \\
\hline $\begin{array}{c}\text { Diameter } \\
\text { (size) }[\mathrm{mm}]\end{array}$ & 4.1 & 7.9 & 11.2 & 9.5 & 20 & 10 & $32 \times 31$ & $9 \times 9$ & $9 \times 9$ & 30 \\
\hline $\begin{array}{c}\text { Thickness } \\
{[\mathrm{mm}]}\end{array}$ & 4.1 & 7.9 & 5.1 & 3.8 & 2.0 & 3.0 & 9.0 & 3.0 & 3.0 & 3.0 \\
\hline
\end{tabular}

TABLE 2

MATERIAL NAMES AND YOUNG'S MODULUS OF THE CUSHION MATERIALS

\begin{tabular}{|c|c|c|c|}
\hline Name & Material & Product name, Corporation & Young's modulus [kPa] \\
\hline Beads1 & Plastic (PP) & & $\sim 30000$ \\
\hline Beads2 & Plastic (PP) & PS-10R, Exseal Corp. & $\sim 30000$ \\
\hline Rubber1 & Poly urethane & PS-8R, Exseal Corp. & $\sim 1000$ \\
\hline Rubber2 & Poly urethane & CN-102, Waki company & $\sim 1000$ \\
\hline Sponge & Urethane rubber & & $\sim 100$ \\
\hline Plastic Plate & Plastic (PVC) & HC-100PL, Catch-cool, Try & \\
\hline Ice Pack & Polymeric water-absorbing polymer & & \\
\hline Air Cushion & Air and thin vinyl & Super gel shock absorbing \\
sheet, ACTIKA Corp. & $\sim 20000$ \\
\hline Gel1 & Styrene elastomer & GEL7, Seiwa-pro Corp. & $\sim 200$ \\
\hline Gel2 & Urethane elastomer & \\
\hline
\end{tabular}


The experiment process was divided into three phases.(1) Contact phase: The sensor probe was approached to the target surface by using the linear actuator with a low speed (about $1 \mathrm{~mm} / \mathrm{sec}$ ) and it stops the linear actuator when the force sensor changes over 6 S.D. from the $0 \mathrm{~N}$. In the system, the base noise of the force sensor is $0.0005 \mathrm{~N}(6 \mathrm{~S} . \mathrm{D} .=$ about $0.003 \mathrm{~N})$. $(2)$ Pushing $3 \mathrm{~mm}$ constant distance: The force sensor was pushed $3 \mathrm{~mm}$ constant distance to the target material. The linear actuator's ball screw mechanism realizes the constant distance control by not difficult control algorithm. The bang-bang control for controlling the force sensor distance was used.(3) Waiting until the force curve is attenuated: After the pushing process, the position of the sensor probe was fixed with $7 \mathrm{sec}$. The sensor probe was pushed 3 mm with the longitudinal direction of the target foam sponge (Fig.5a), and it was repeated five times. By changing the kind of cushion (Beads1 to Plastic plate), the measurement force and the stability were confirmed.
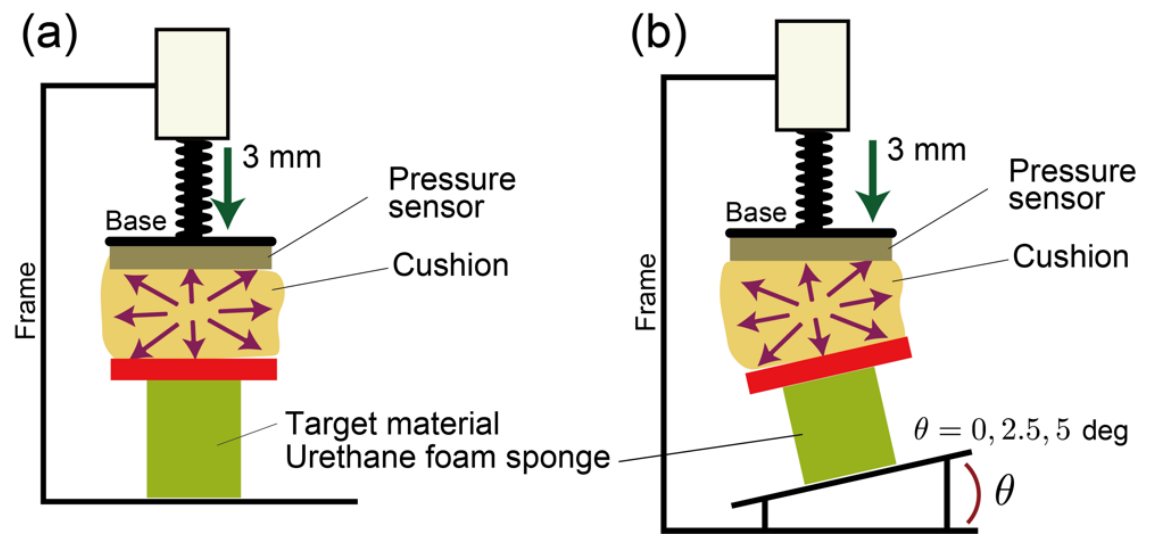

FIGURE 5. EXPERIMENT SETUP CONDITIONS OF (a) EXPERIMENT 1AND (b) EXPERIMENT 2.

\subsection{Experiment 2: Dependencies of the sensor probe angle}

In experiment 2, the dependencies of the sensor probe angle were examined using (a) Plastic plate and (b) Gel2 in Table 1 as the cushion. The experiment process was same with experiment 1.

\section{RESULT}

The result of experiment 1 was shown in Table 3 and Fig.6. The force $F$ represents the average of the PTF sensor output after $7 \mathrm{sec}$ attenuation when $3 \mathrm{~mm}$ pushing process, and S.D. of $F$ means the standard deviation of the $F(\mathrm{~N}=5)$. Since the $F$ was not taken a constant value, the S.D. of $F$ was normalized by $F$ using formula $\frac{S . D . o f F}{F}=s$ and the result was summarized in Table 3 and Fig. 6. When the value takes a low value, it means the measurement was a stable one.

The result was summarized below: (1) When the cushion was hard material (Beads1, Beads2), $s$ takes a high value (>0.3) though the shape of the cushion is a sphere (Table3 and Fig. 6).It means that to reduce the effect of angle dependencies of the sensor probe, the point contact (because it is a sphere) has not better effects to the sensor output of the PTF. (2)Round shape polyurethane rubber (Rubber1, Rubber2) result takes almost same or relatively small value of $s$. It means that in the range of $1000 \mathrm{kPa}$ material, the shape of the cushion was not important. (3) To comparing the previous study of the indirect pressure measurement of a human body (mannequin) [34] (Fig.3b), small sized Ice pack (Fig. 6B) was used, and the result was good comparing with Sponge (100 kPa) or Plastic plate (50000 kPa, Fig. 6A).(4) Soft materials (Air Cushion, Gel1, Gel2) got good performance (around 0.13) of $s$. It means that about $200 \mathrm{kPa}$ range of Young's modulus was necessary to measure the hardness of the urethane foam sponge (about $20 \mathrm{kPa}$ ).

TABLE 3

RESULT OF EXPERIMENT 1

\begin{tabular}{|c|c|c|c|c|c|c|c|c|c|c|}
\hline & Beads1 & Beads2 & Rubber1 & Rubber2 & Sponge & Plastic plate & IcePack & Air Cushion & Gel1 & Gel2 \\
\hline Picture & olliाIII, & & & . & & & & (s) & olin!IIII! & 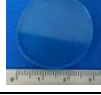 \\
\hline $\mathrm{F}[\mathrm{N}]$ & 1.32 & 1.3 & 1.4 & 2.05 & 2.31 & 2.03 & 2.79 & 2.7 & 2.78 & 3.1 \\
\hline $\begin{array}{c}\text { S.D. of F } \\
{[\mathrm{N}]}\end{array}$ & 0.45 & 0.43 & 0.46 & 0.48 & 0.44 & 0.37 & 0.49 & 0.37 & 0.38 & 0.39 \\
\hline $\begin{array}{l}\text { Normalize } \\
\text { S.D. by F }\end{array}$ & 0.34 & 0.32 & 0.33 & 0.23 & 0.19 & 0.18 & 0.17 & 0.14 & 0.14 & 0.13 \\
\hline
\end{tabular}




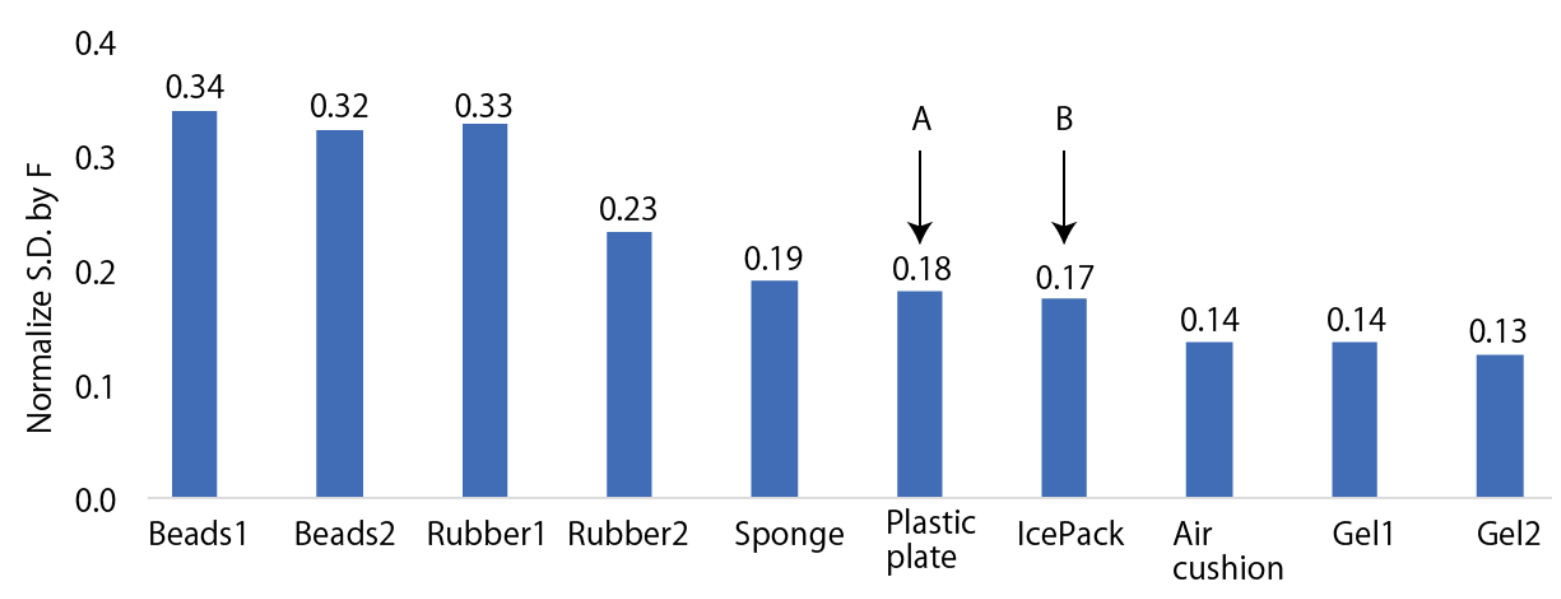

\section{FIGURE 6. NORMALIZED STANDARD DEVIATION BY F OF THE RESULT OF EXPERIMENT 1}

The result of experiment 2 was shown in Fig.7. Fig. 7(a) was the case of the Plastic plate as the cushion. The output force value $F$ was measured in the case of $3 \mathrm{~mm}$ pushing while $10 \mathrm{sec}$. The reason of using the Plastic plate was that even if Young's modulus takes a high value, the $s$ was measured as a small value. This characteristic mainly depended on the size of the plate, and the $9 \times 9 \mathrm{~mm}$ size plate led maximum performance in our experimental setup (it related to the size of the PTF sensor). However, in the case of the Plastic plate cushion, the $F$ was decreased by the change of the pushing angle (the condition was Fig.5b), and the force convergence curve was not stable. On the other hand, Fig. 7(b) shows the case of Gel1, and it was converged one value $(3.18 \pm 0.08 \mathrm{~N}, \mathrm{~N}=5)$ in each angle settings.

(a)
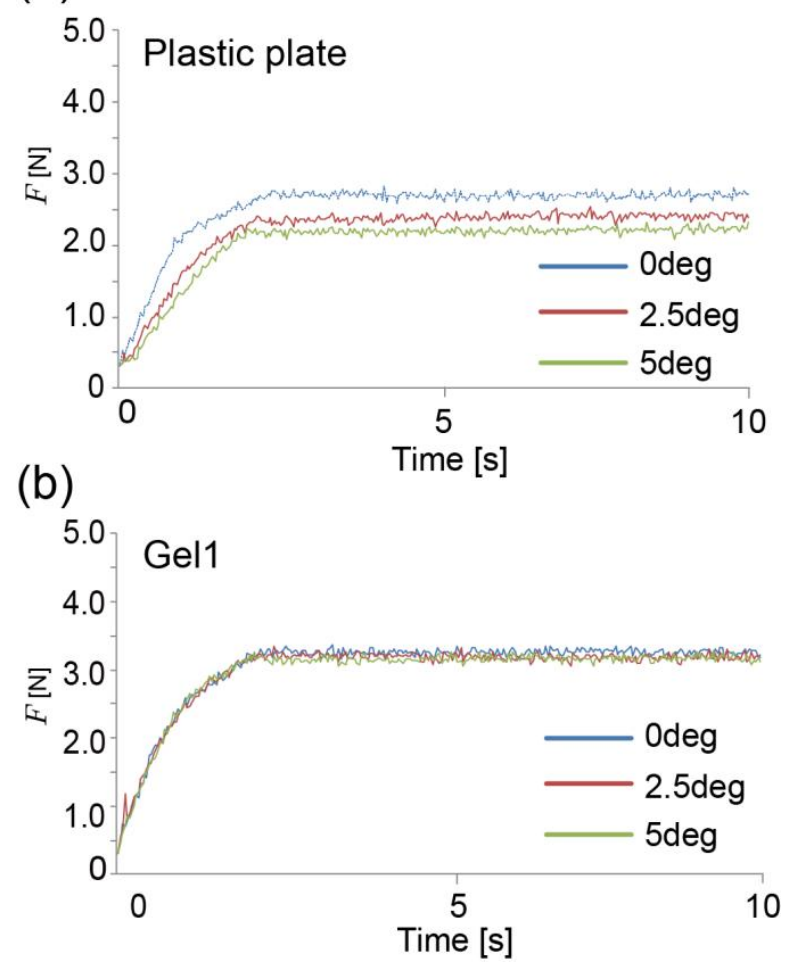

Figure 7. RESUlt OF EXPERIMENT 2. THE CASE OF PLASTIC PLATE AND GEL1.

\section{CONCLUSION}

In this study, experimental study of hardness measurement process affected by a cushion between the probe contact terminal and PTF pressure sensor was discussed. The result of experiment 1 shows that the material kind of the cushion is important for the stable measurement of the force. Shock-absorbing gel (Gel1, Gel2) was effectively work for transmitting the pushing force to the PTF sensor surface. The result of experiment 2 shows that the pushing angle of the sensor probe was affected to the force measurement and the divergence of the force could be suppressed by using shock absorbing gel (Gel1, Gel2). This result would be useful for developing a low-cost hardness measurement system for soft material. 


\section{REFERENCES}

[1] M. Taguchi, G. Nakajima, S. Maeda, T. Yoshino, "Toward to ensure fruit and vegetables of safety and security - the use of fruits and vegetables of the traceability system", ISFJ Japan policy Student Conference, 2010.

[2] K. Sakamoto, Y. Muratani, S. Omata, "Fundamental research on the development of surgical support device", SICE Tohoku branch, No. 198 Workshop, 198-9, pp.1-4, 2001.

[3] M. Tanaka, T. Adachi, Y. Tanahasi, S. Chonan, "Development of An active Palpation Sensor for Detecting Prostatic Cancer and Hypertrophy", Japan Society of Mechanical Engineers, Annual Conference Papers (I), 2002.

[4] A. Shigetaka, H. Takashi, H. Eiichiro, M. Kazuhiko, K. Shinken, "Non-invasive Measurement of Intracranial Pressure via the Anterior Fontanelle: New Method for Fixation of the Measuring Apparatus", Neurologia medico-chirurgica, Vol. 26(4), pp. 291-295, 1986-0415.

[5] E. Honda, T. Hayashi, T. Masasima, S. Anegawa, T. Kikukawa,"A New Instrument for Non-invasive Measurement of Intracranial Pressure via the Anterior Fontanelle.", Neurol. Med. Chir., Vol. 22, pp.640-648, 1982.

[6] I. Kato, K. Koganezawa, A. Takanishi, "Automatic Palpation System for Breast Cancer: WAPRO-4", Journal of the Robotics Society of Japan, Vol. 5(2), pp.102-108, 1987.

[7] H.G. Muller, "An lntroduction to Food Rheology", pp. 1-16, 1973.

[8] American Association of Cereal Chemists: Cereal laboratory methods, Staleness of bread compression test with baker compressimeter, AACC Method, Vol. 74-10, 1961.

[9] D.W.E Axford , K. H. Colwell , S.J. Conford , G.A.H. Elton , "Effect of loaf specific volume on the rate and extent of staling in bread", Journal of Science of Food and Agriculture, Vol. 19, pp. 95-101, 1968.

[10] Neuroinfo Japan HP, "Neurosurgical disease information", available from <http://square.umin.ac.jp/neuroinf/medical/601.html>, (accessed 2017-10-31).

[11] Japan hydrocephalus Association, "hydrocephalus Guidebook 2002", available from <http: // www.suitoushou.net/guide.html>, (accessed 2017-10-31).

[12] M. Tanaka, M. Tamura, T. Okuyama, "Study on a roller scanning type palpation sensor", International Journal of Applied Electromagnetics and Mechanics, DOI: 10.3233/JAE-141899, Vol. 45, No. 1-4, pp. 723-729, 2014.

[13] K. Maeda, "Occupational Cervicobrachial disorder and its causative factors", J. Human Ergol., Vol. 6 (2), pp. 192-202, 1977.

[14] F. Sakai, S. Ebihara, M. Akiyama, H. Horikawa, "Pericranial muscle hardness in tension-type hcadache; A non-invasive measurement method and its clinical application", Brain, Vol. 118, pp. 523-531, 1995.

[15] M. Horikawa, "Effect of visual terminal height on the trapezius muscle hardness: quantitative evaluation by a newly developed muscle hardness meter", Applied Ergonomics, Vol. 32, pp. 473-478, 2001.

[16] J. L. Gennisson, C. Cornu, S. Catheline, M. Fink, P. Portero, "Human muscle hardness assessment during incremental isometric contraction using transient elastography", Journal of Biomechanics, Vol. 38 (7), pp. 1543-1550, 2005.

[17] O. Yanagisawa, M. Niitsu, T. Kurihara, T. Fukubayashi, "Evaluation of human muscle hardness after dynamic exercise with ultrasound real-time tissue elastography: A feasibility study", Clinical Radiology, Vol. 66, No.9, pp. 815-819, 2011.

[18] U. Bindig, I. Gersonde, M. Meinke, Y. Becker, G. Muller, "Fibre - optic IR - spectroscopy for biomedical diagnostics", Spectroscopy, Vol. 17, No. 2,3, pp. 323-344, 2003.

[19] N. Tomotake, H. Watanabe, J. Matuoka, Y. Jinou, R. Koga, "A study of static stretching time and its effect of using the muscle hardness tester", Japanese Journal of Sports Injuries, Vol. 17, pp.37-39, 2012.

[20] T. Koeda,"Hardness measurement of vivo by muscle hardness meter - reproducibility and validity and usefulness -", Nagoya Gakuin University Studies, humanities and natural sciences (Japanese), Vol. 46, No. 2, 2010.

[21] S. Suzuki et al., "Individual Muscle Stretching", ISBN978-4-89590-475-9, pp.36-39, 2006.

[22] O. Ooshiro, et al., "Analysis of local elastic modulus in MR Elastography of using the instantaneous frequency method", MEDICAL IMAGING TECNOLOGY, Vol.18, No.2, 2000

[23] M. Nagao, T. Endo, O. Yokota, "Correlation between Questionnaire Survey and Muscle Hardness in Shoulder Stiffness", SICE Tohoku Branch No. 268 Workshop, 268-6, 2011.

[24] D. Ishikawa, T. Uchiyama, "Development of portable digital muscle hardness meter using indentation method", Bio mechanism Journal, Vol. 30 (4), pp. 234-237, 2006-11-01.

[25] Kind of hardness sensor, Elastron HP, available from <http:// www.elastron.co.jp / about.html>, (accessed on 2017-10-31).

[26] T.M. Junisbekov, "Stress Relaxation in Viscoelastic Materials", ISBN 1-57808-258-7, 2003

[27] S. Moromugi, S. Kumano, M. Ueda, T. Ishimatsu, M. Q. Feng, T. A. Tanaka, "Sensor to measure hardness of human tissue", Sensors, 2006, 5th IEEE Conference on 2006, DOI: 10.1109/ICSENS.2007.355487, pp. 388 - 391, 2006.

[28] T. Koeda,"Hardness measurement of vivo by muscle hardness meter - reproducibility and validity and usefulness -", Nagoya Gakuin University Studies, humanities and natural sciences (Japanese), Vol. 46, No. 2, 2010.

[29] Y. Maeda, K. Terao, T. Suzuki, F. Shimokawa, H. Takao, "A tactile sensor with the reference plane for detection abilities of frictional force and human body hardness aimed to medical applications", Micro Electro Mechanical Systems (MEMS), 2015 28th IEEE International Conference on 2015, pp. 253-256, DOI: 10.1109/MEMSYS.2015.7050936, 2015.

[30] Z. Shenshen, D. Parks, L. Chang, "Design and Modeling of a Wide Dynamic-Range Hardness Sensor for Biological Tissue Assessment", Sensors Journal, IEEE, Vol.13, Issue 12, DOI:10.1109/JSEN.2013.2271736, pp. 4613-4620, 2013. 
[31] L. Zizhen, K. Yeung, "On Preconditioning and Stress Relaxation Behaviour of Fresh Swine Skin in Different Fibre Direction", International Conference on Biomedical and Pharmaceutical Engineering 2006, ICBPE 2006, pp.221-226, 2006.

[32] O. Motoki, T. Hideki, "Development of softness measurement technique using a flexible probe and a constant distance pushing for infant hydrocephalus inspection", The Robotics and Mechatronics Conference 2015, ROBOMECH2015 in Kyoto, ID: 19921203, 2015.

[33] O. Motoki, T. Hideki, "Proposal of Low Deformation Hardness Sensing Method by Constant-Displacement Pushing without Force Control", International Conference of u-Healthcare 2015, Kinki University Japan, Nov.30-Dec.2, P1-19, 2015.

[34] T. Satoru, T. Jin, O. Akihiro, "Full scale model experiment on working pressure at burial sediment", (japanese), Society of Biomechanisms Japan, SOBIM 2016, Toyama, pp. 213-216, 2016. 